\title{
NFATc3 mediates the sensitivity of gastric cancer cells to arsenic sulfide
}

\author{
Xiuli Zhang ${ }^{1}$, Ting Kang ${ }^{1}$, Lian Zhang ${ }^{1}$, Yingying Tong ${ }^{1}$, Wenping Ding ${ }^{1}$ and Siyu Chen ${ }^{1}$ \\ ${ }^{1}$ Department of Oncology, Xin Hua Hospital Affiliated to Shanghai Jiao Tong University School of Medicine, Shanghai, China \\ Correspondence to: Siyu Chen, email: siyu.chen@shsmu.edu.cn \\ Keywords: $\mathrm{As}_{4} \mathrm{~S}_{4^{\prime}}$ NFATC3, C-MYc, sensitivity, gastric cancer \\ Abbreviations: $\mathrm{As}_{4} \mathrm{~S}_{4}$ : arsenic sulfide; NFAT: nuclear factor of activated T cells; GC: gastric cancer; PML: promyelocytic leukemia \\ Received: December 07, $2016 \quad$ Accepted: March 03, $2017 \quad$ Published: April 18, 2017
}

Copyright: Zhang et al. This is an open-access article distributed under the terms of the Creative Commons Attribution License 3.0 (CC BY 3.0), which permits unrestricted use, distribution, and reproduction in any medium, provided the original author and source are credited.

\section{ABSTRACT}

Arsenic sulfide $\left(\mathrm{As}_{4} \mathrm{~S}_{4}\right)$ is the main component of Realgar which is widely used in traditional Chinese medicine. Previously we showed that $\mathrm{As}_{4} \mathrm{~S}_{4}$ inhibited the proliferation of colon cancer cells through regulating nuclear factor of activated T cells (NFAT) pathway. Here we explore the role of NFAT in gastric cancer. We showed that $\mathrm{As}_{4} \mathrm{~S}_{4}$ inhibited the expression of NFATc1, NFATc3, and NFATc4, and modulated the expression of NFATc2 accompanying with p53. The baseline expression of NFATc3 varied distinctly in gastric cancer cell lines (AGS, MGC803, MKN28, MKN45, and SGC7901) and the sensitivity of these cells to $\mathrm{As}_{4} \mathrm{~S}_{4}$ was dissimilar, with AGS and MGC803 cells showing higher sensitivity while the SGC7901 cells relatively resistant. Interestingly, the sensitivity to $\mathrm{As}_{4} \mathrm{~S}_{4}$ was correlated with the level of expression of NFATc3, and the cells relatively sensitivity just showing higher expression of NFATc3. Furthermore, NFATc3 expression was significantly higher in gastric cancer tissues compared with the adjacent normal tissues. Our data also showed that, NFATc3 promoted the proliferation of gastric cancer cells by regulating c-Myc. In conclusion, $\mathrm{As}_{4} \mathrm{~S}_{4}$ inhibited the proliferation of gastric cancer cells through NFATc3/c-Myc pathway and the diverse sensitivity among different cell lines correlated with the expression level of NFATc3 indicating that NFATc3 may be a potential therapeutic target in gastric cancer.

\section{INTRODUCTION}

Gastric cancer (GC) is an important malignant disease associated with very poor prognosis and the second leading cause of cancer-associated death worldwide, and almost half of all GC cases occur in Asia [1]. Presently, surgical resection and adjuvant or neoadjuvant chemotherapy and radiation remain the principle treatment options of early stage GC [2]. However, the mainstay therapy for the advanced stage GC is systemic chemotherapy, with the 5 -year overall survival less than $20 \%$ [3]. Recent studies indicate that aberrant expression of a number of genes is associated with gastric carcinogenesis and cancer progression. For example, neogenin-1 promotes gastric cancer cell proliferation and motility, and an IL-17 polymorphism might be the main risk factor for gastric cancer in China and Japan [4, 5]. Therefore, a more thorough understanding of the molecular mechanisms underlying GC development and progression can help improve the treatment and outcome of patients with GC. Nuclear factor of activated T cells (NFAT) was first identified as a transcription factor binding to the interleukin-2 promoter in human T cells $[6,7]$. Since then, various NFAT isoforms including NFATc1, NFATc2, NFATc3, NFATc4, and NFAT5 have been identified and characterized. Expression of NFATs is not restricted to T cells, with other cells and tissuesincluding muscle, bone, neurons, viscera, and skin - all producing various NFATs [8-11]. The biological functions of NFATs include angiogenesis, cardiovascular development, immune regulation, and bone homeostasis. Additionally, recent studies suggest roles for NFATs in the initiation and progression of cancer, with cancer cell proliferation, invasion, metastasis, drug resistance, and the tumor microenvironment all influenced by NFATs [12-14]. For example, NFATc1 promotes proliferation of hepatocellular 
carcinoma cells [15], NFATc2 increases the invasiveness of breast cancer cells [16], and NFATc3 and NFATc4 promote the progression of colon cancer [17]. Contrastingly, other studies have shown that NFATc2 and NFATc3 can act as tumor suppressors $[18,19]$. These findings indicate that the precise functions of different NFATs in cancer are contextdependent.

Our previous study has shown that arsenic sulfide $\left(\mathrm{As}_{4} \mathrm{~S}_{4}\right)$ can regulate NFAT gene expression via the promyelocytic leukemia (PML) and p53 pathways in solid tumor cells [17]. Our current study describes a novel role for NFATc3 in GC. We found that $\mathrm{As}_{4} \mathrm{~S}_{4}$ could inhibit GC cell proliferation, and that the sensitivity of these cells to $\mathrm{As}_{4} \mathrm{~S}_{4}$ was significantly different. Consistent with our previous studies, $\mathrm{As}_{4} \mathrm{~S}_{4}$ modulated the expression of NFATs [17], while the baseline expression of NFATc3 was diverse among cell lines. Furthermore, NFATc3 levels were higher in GC tissues compared with corresponding adjacent normal tissues, and NFATc3 suppressed proliferation of GC cells by regulating c-Myc. Importantly, cells with higher NFATc3 expression levels were more sensitive to $\mathrm{As}_{4} \mathrm{~S}_{4}$, while cells with lower NFATc3 expression levels were relatively resistant to $\mathrm{As}_{4} \mathrm{~S}_{4}$. Moreover, the sensitivity of $\mathrm{GC}$ cells to $\mathrm{As}_{4} \mathrm{~S}_{4}$ changed when the expression level of NFATc3 was altered. These findings suggest that expression levels of NFATc3 influence the sensitivity of GC cells to $\mathrm{As}_{4} \mathrm{~S}_{4}$, suggesting a potential role for $\mathrm{As}_{4} \mathrm{~S}_{4}$ as an anti-cancer therapeutic in appropriate patients.

\section{RESULTS}

\section{$\mathrm{IC}_{50}$ values of $\mathrm{As}_{4} \mathrm{~S}_{4}$ vary among $\mathrm{GC}$ cell lines}

We previously reported that AGS and MGC803 have different sensitivities to $\mathrm{As}_{4} \mathrm{~S}_{4}$, and that both cell lines were more sensitive than the human gastric epithelium cell line GES-1. The $24 \mathrm{~h} \mathrm{IC}_{50}$ values of $\mathrm{As}_{4} \mathrm{~S}_{4}$ for AGS and MGC803 cells were 2.69 and $3.26 \mu \mathrm{M}$, respectively [20]. Therefore, here we treated additional GC cell lines-MKN28, MKN45, and SGC7901—with increasing concentrations of $\mathrm{As}_{4} \mathrm{~S}_{4}(0,2.5,5,10$, and $20 \mu \mathrm{M})$ for 24 , 48 , or $72 \mathrm{~h} . \mathrm{As}_{4} \mathrm{~S}_{4}$ inhibited the proliferation of all GC cells in a time- and dose-dependent manner. Additionally, the $24 \mathrm{~h} \mathrm{IC}_{50}$ values for MKN28, MKN45, and SGC7901 cells were $11.71,16.77$, and $20.8 \mu \mathrm{M}$, respectively (Figure $1 \mathrm{~A}-1 \mathrm{C})$. Figure $1 \mathrm{D}$ demonstrates that the $24 \mathrm{~h} \mathrm{IC}_{50}$ values of $\mathrm{As}_{4} \mathrm{~S}_{4}$ for $\mathrm{GC}$ cells varied by almost ten-fold, and that AGS and MGC803 cells were relatively sensitive, while SGC7901 cells were relatively resistant.

\section{NFAT protein levels in GC cells are modulated by $\mathrm{As}_{4} \mathrm{~S}_{4}$}

We have previously revealed that NFAT proteins are targets of $\mathrm{As}_{4} \mathrm{~S}_{4}$ in multiple types of cancer cells including GC cells [17]. Figure 2A shows that treatment of AGS cells with $\mathrm{As}_{4} \mathrm{~S}_{4}$ inhibited the expression of NFATc1, NFATc3, and NFATc4, and increased that of NFATc2. Meanwhile, c-Myc was down-regulated and p53 up-regulated. We previously identified similar results in MGC803 cells, except that differential modulation of NFATc2 was identified. This is likely because AGS cells express intact p53, while MGC803 cells have mutated p53 [17].

\section{Baseline expression of NFATc3 varies dramatically among GC cell lines}

We next examined the role of specific members of NFAT family in GC. We first measured the baseline expression levels of NFAT the family members NFATc1, NFATc2, NFATc3, and NFATc4. Western blotting revealed that NFATc3 was expressed at much higher levels in AGS and MGC803 cells compared with SGC7901 cells (Figure 2B). Therefore, GC cells relatively sensitive to $\mathrm{As}_{4} \mathrm{~S}_{4}$ (AGS and MGC803) had higher expression levels of NFATc3, while relatively resistant SGC7901 cells had lower levels of NFATc3. However, levels of other NFAT proteins did not exhibit a relationship with cells sensitivity to $\mathrm{As}_{4} \mathrm{~S}_{4}$ (Supplementary Figure 1).

\section{NFATc3 expression levels are higher in GC tissue compared with adjacent normal tissue}

We next evaluated NFATc 3 expression in 20 cases of GC samples and the corresponding adjacent normal tissues by real time quantitative PCR. Significantly higher levels of NFATc3 were detected in GC samples than in corresponding non-tumor tissues (Figure 3A, $P$ $<0.01)$. These findings suggest that NFATc 3 may serve as an oncogene in GC and the expression of NFATc3 may play an important role in the pathogenesis and development of GC.

\section{NFATc3 can promote GC cell proliferation in vitro}

We investigated the function of NFATc3 in GC tumorigenesis by infecting AGS and MGC803 cells with lentiviruses carrying NFATc3 shRNA, and transfecting SGC7901 cells with plasmid expressing NFATc3 tpRNA. Figure 3B-3D reveals that knockdown of NFATc3 in AGS and MGC803 cells significantly inhibited colony formation, while over-expression of NFATc3 in SGC7901 cells promoted colony formation. Taken together, these findings indicate that NFATc 3 promotes the proliferation of GC cells.

\section{NFATc3 modulates other members of the NFAT family and may promote GC cell proliferation through c-Myc}

We next investigated the mechanisms of how NFATc3 regulates GC cells by measuring expression 
levels of other NFAT family members after knockdown or over-expression of NFATc3. Knockdown of NFATc3 in AGS and MGC803 cells downregulated NFATc1, NFATc4, and the oncogene c-Myc (Figure 4A, 4B). Meanwhile, over-expressing NFATc3 in SGC7901 cells up-regulated NFATc1, NFATc4, and c-Myc (Figure 4C). These findings reveal interactions between NFAT family members, and suggest that NFATc3 may promote the proliferation of GCs in vitro by using c-Myc as one of its target genes.

\section{The sensitivity of GC cells to $\mathrm{As}_{4} \mathrm{~S}_{4}$ is associated with the baseline expression of NFATc3}

Finally, we examined whether the $\mathrm{IC}_{50}$ values for $\mathrm{As}_{4} \mathrm{~S}_{4}$ were altered by changes to NFATc3 levels. Figure 5 shows that the 24-h $\mathrm{IC}_{50}$ values of $\mathrm{As}_{4} \mathrm{~S}_{4}$ for AGS and MGC803 cells in which NFATc3 had been silenced were

A

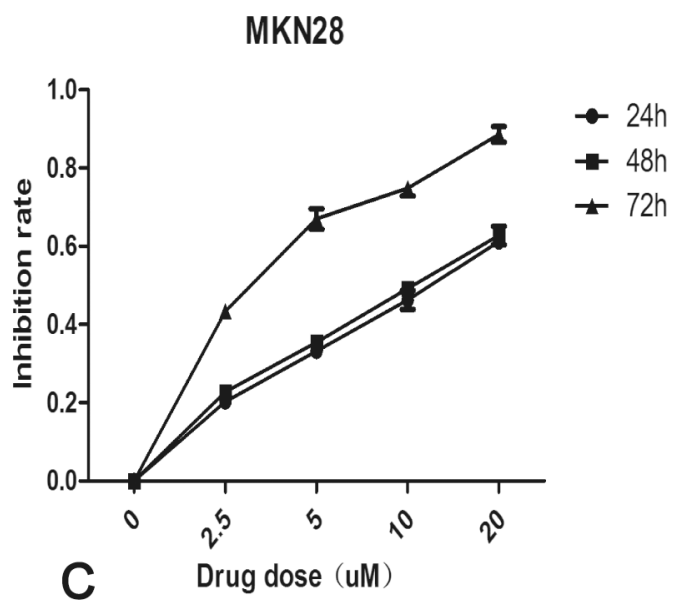

SGC7901

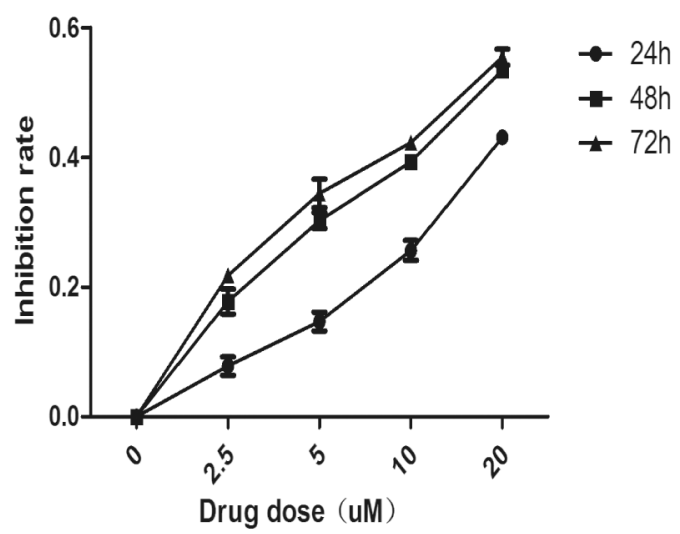

26.06 and $20.12 \mu \mathrm{M}$, respectively. These findings reflect decreases in the sensitivity of AGS and MGC803 cells to $\mathrm{As}_{4} \mathrm{~S}_{4}$ of 9.69- and 6.17-fold, respectively. Meanwhile, over-expression of NFATc3 in SGC7901 cells decreased the 24-h $\mathrm{IC}_{50}$ of $\mathrm{As}_{4} \mathrm{~S}_{4}$ from 20.8 to $14.59 \mu \mathrm{M}$ (Figure $6)$. These results reveal that the GC cells with higher expression levels of NFATc3 are more sensitive to $\mathrm{As}_{4} \mathrm{~S}_{4}$.

\section{DISCUSSION}

GC is an aggressive neoplasm with high prevalence, poor prognosis, and limited treatment options [21]. Furthermore, half of cases worldwide occur in China. Presently, the efficacy of chemotherapeutic drugs in clinical use for the treatment of advanced-stage GC is unsatisfactory. Therefore, there is an urgent need to identify the key factors involved in the disease progression

B

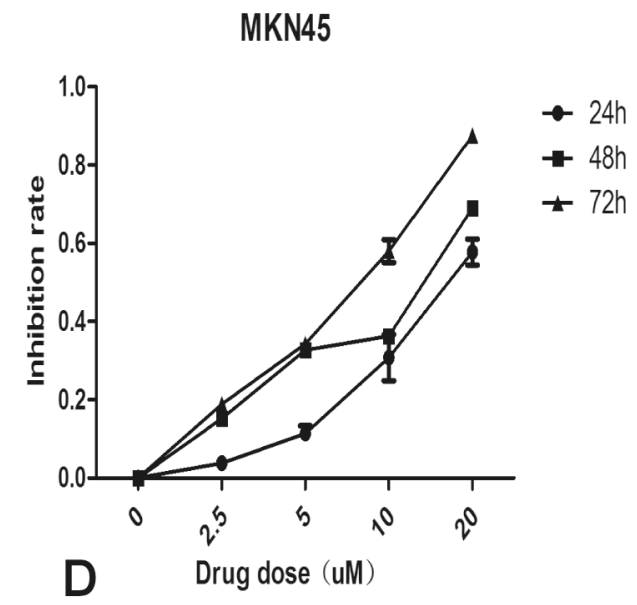

24h IC50 of GC cells of $\mathrm{As}_{4} \mathrm{~S}_{4}$

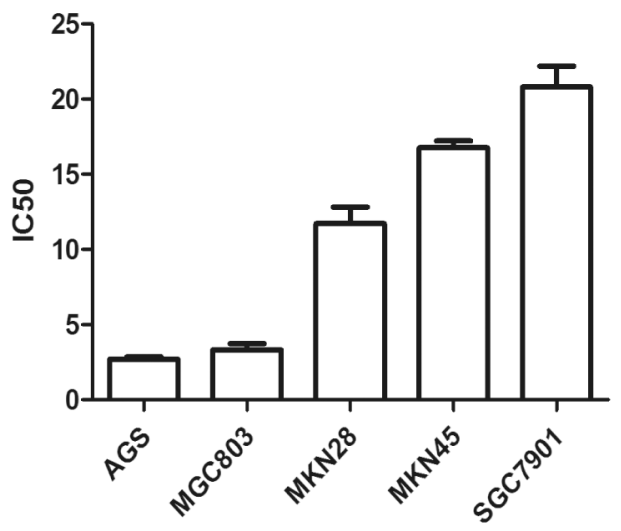

Figure 1: Curves of cell inhibition rates in gastric cancer cells treated with $\mathbf{A s}_{4} \mathbf{S}_{4}$. (A-C) Dose-and time-dependent curves of cell inhibition rates in cells treated with $\mathrm{As}_{4} \mathrm{~S}_{4},(\mathbf{A}-\mathbf{C})$ represent MKN28, MKN45, SGC7901, respectively. (D) The comparisons of the IC 50 to $\mathrm{As}_{4} \mathrm{~S}_{4}$ of five gastric cancer cells. Data represent the mean \pm standard deviation of three independent experiments. 
A

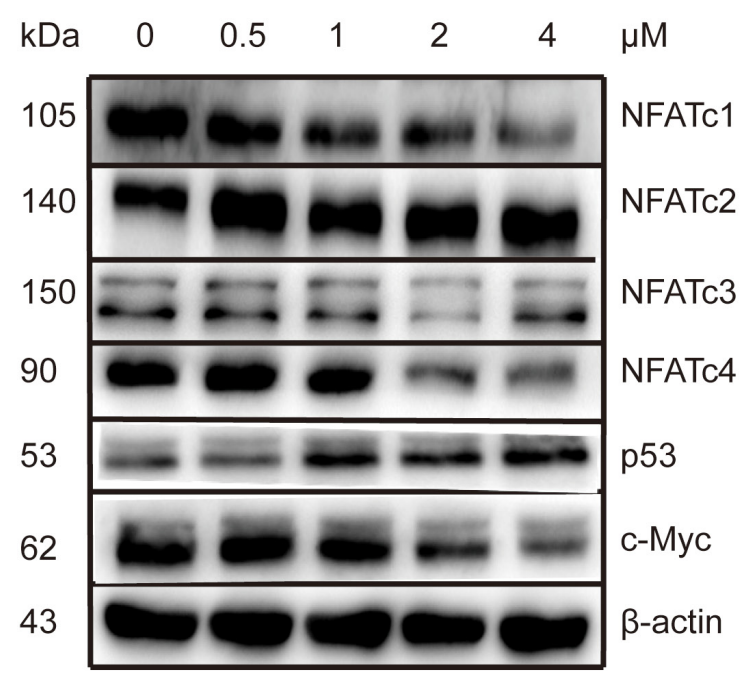

B

kDa AGS MGC803 MKN28 MKN45 SGC7901

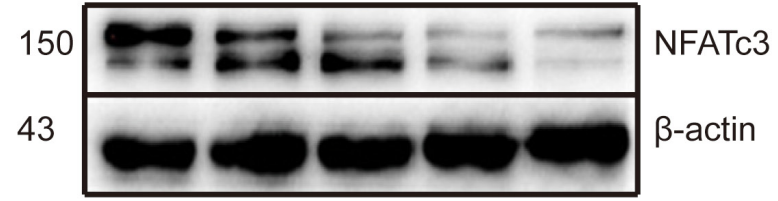

C

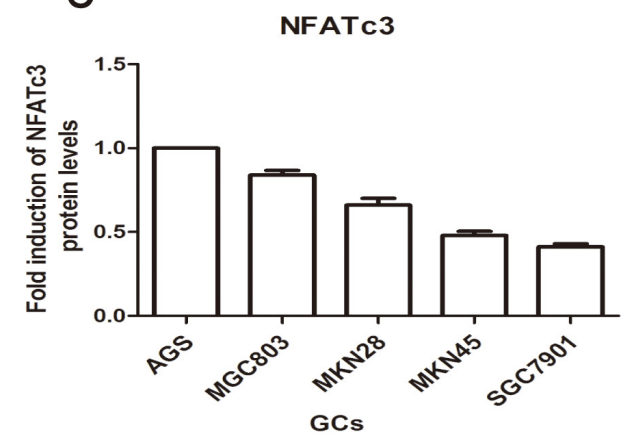

Figure 2: $\mathrm{As}_{4} \mathrm{~S}_{4}$ modulated the NFAT protein level; the baseline expression of NFATc3 among GC cell-lines. (A) AGS cells were treated with $\mathrm{As}_{4} \mathrm{~S}_{4}$ in different concentration for 24 hours and NFATc1, NFATc3, NFATc4 and c-Myc were down-regulated while NFATc2 and p53 were up-regulated. (B) The baseline expression of protein NFATc3 in AGS, MGC803, MKN28, MKN45 and SGC7901 cells was various distinctly. (C) Protein quantification of the Western blot results shown in (B), NFATc3 protein levels were normalized to the $\beta$-actin levels and are shown as fold changes relative to the levels of AGS which is as control strain.

A

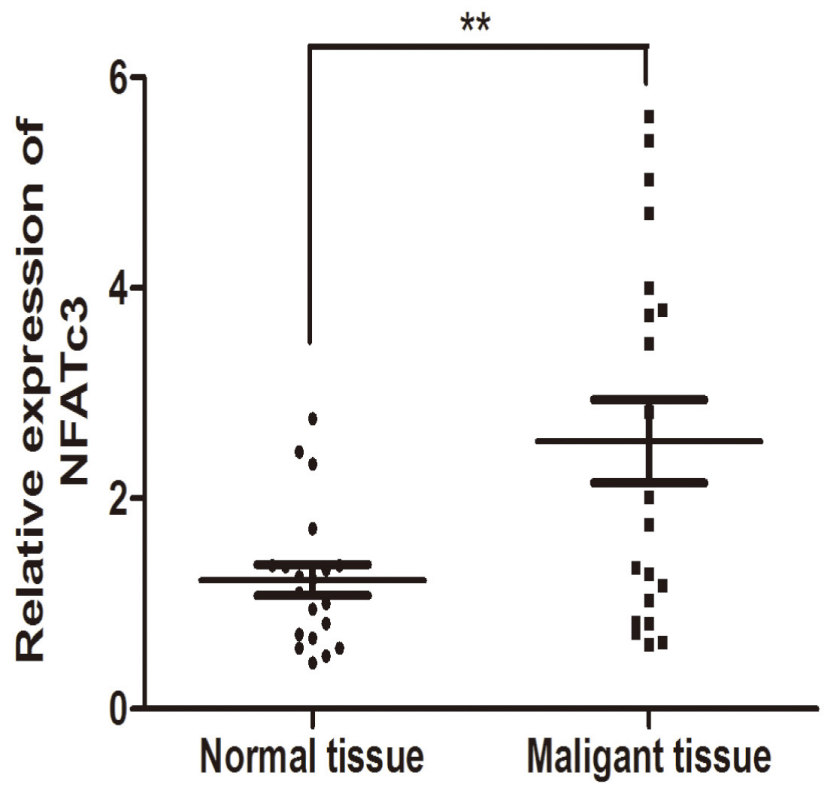

B control shRNA NFATc3 shRNA

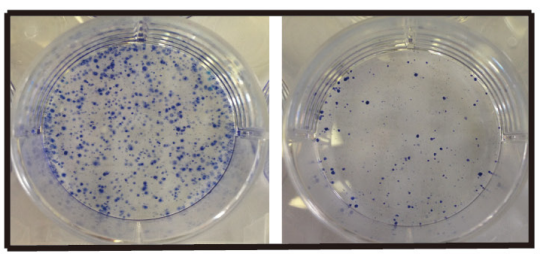

C
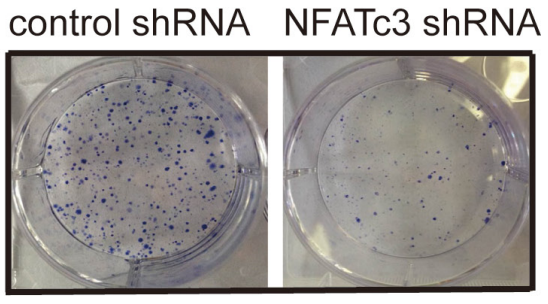

D

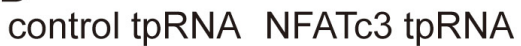

Figure 3: The effect of NFATc3 in GC. (A) Comparative analysis of NFATc3 expression was determined in 20 pairs of tumor tissues and the corresponding adjacent normal tissues by real time quantitative PCR (qRT-PCR). ${ }^{* *} P<0.01$ compared to normal tissues. (B-D) Giemsa staining of colonies after the transfection. (B and C) represent AGS, MGC803 respectively, (D) represents SGC7901. It shows that NFATc3 could promote colony formation and indicates that it plays a pro-proliferation role in GC cells. 
and new effective targets for drug development. Our previous study demonstrated that $\mathrm{As}_{4} \mathrm{~S}_{4}$ can exert antitumor effects in both gastric and colon cancers, and that $\mathrm{As}_{4} \mathrm{~S}_{4}$ regulates the expression of NFAT via PML and p53. Furthermore, we revealed that NFATc3 can promote tumorigenesis by regulating c-Myc [17].

The NFAT family has important roles in modulating biological behavior of malignant tumors [12]. For example, the functions of NFAT family members have been elaborated in pancreatic cancer [22-24], leukemia $[25,26]$, breast cancer [27, 28], and melanoma [29].

However, there are few reports concerning the role of NFAT family members in GC. In addition to their roles in influencing cell proliferation, recent studies have identified important roles for NFAT in modulating drug resistance, NFATc1 over-expression renders pancreatic cancer cells less responsive to treatment with phospho- sulindac [30]. Furthermore, impairment of NFAT activity facilitates leukemia cell elimination by the BCR-ABL inhibitor dasatinib, and NFAT inhibition augments the anti-cancer effects of vemurafenib and trametinib in melanoma [31, 32].

Additionally, inhibition of the calcineurin-NFAT pathway by cyclosporine A reverses resistance to ABT737 in activated T lymphocytes. Meanwhile, others have found that combination treatment of NFAT inhibition with cyclosporine A could reverse resistance to the MEK inhibitor selumetinib in a patient-derived tumor xenograft model of colorectal cancer [33, 34]. However, specific roles for other members of the NFAT family in mediating resistance to anti-cancer drugs have not been described.

Our previous studies indicated that different cancer cells exhibited distinct sensitivities to $\mathrm{As}_{4} \mathrm{~S}_{4}$. Therefore, we collected a series of gastric (AGS, MGC803, MKN28,
A

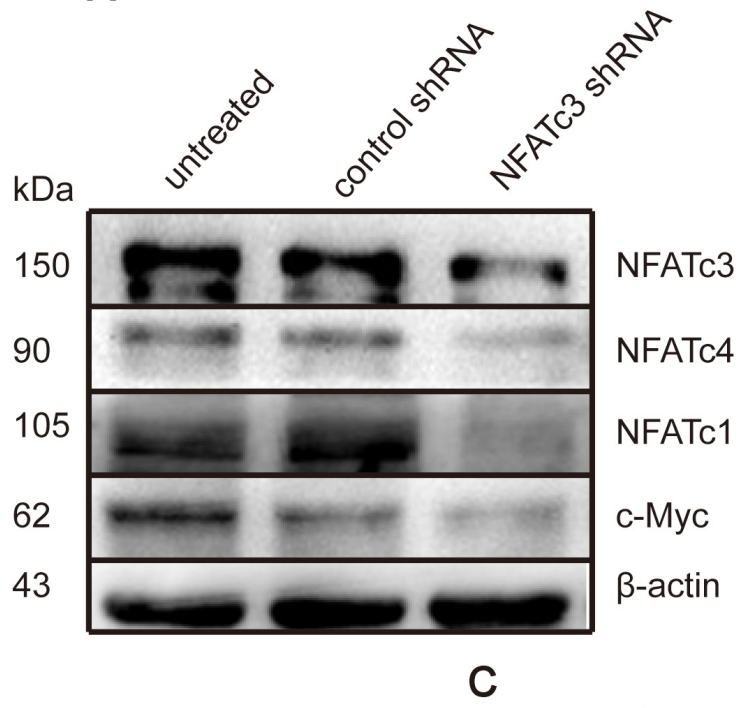

B

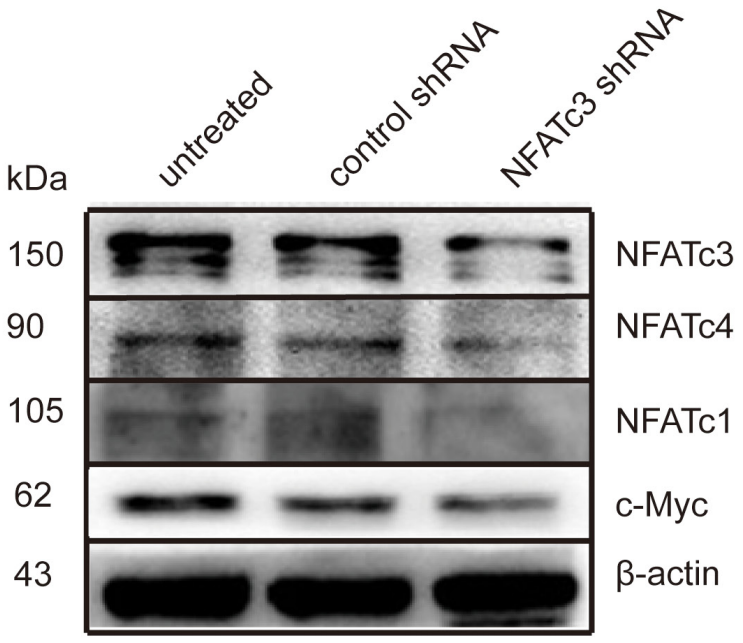

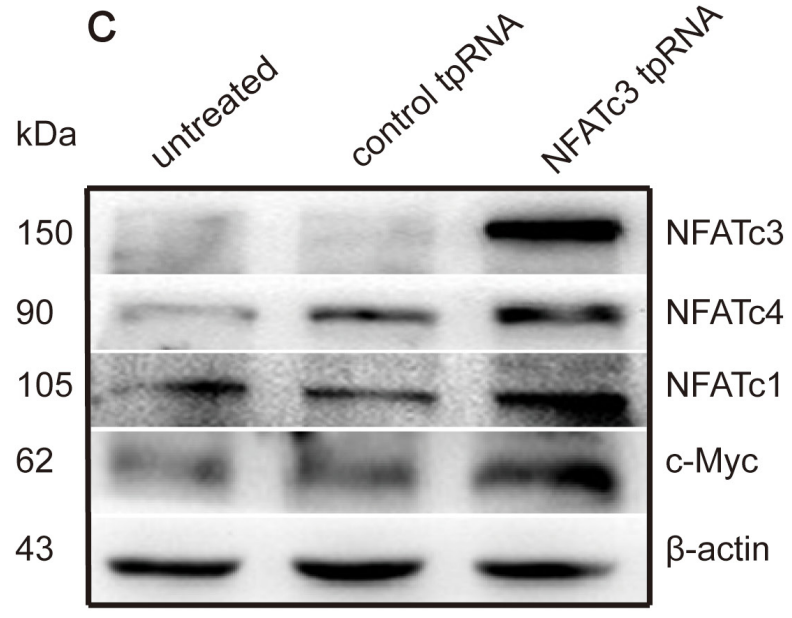

Figure 4: NFATc3 regulated the expression of c-Myc and other members of NFAT family. (A, B) Western blotting shows the expression of c-Myc, NFATc1 and NFATc4 can be suppressed when the cells transfected with Lentiviruses carrying NFATc3 shRNA. (C) Western blotting shows the expression of c-Myc, NFATc1 and NFATc4 can be up-regulated when the cells transfected with plasmid carrying NFATc3 tpRNA. (A-C) represent AGS, MGC803 and SGC7901cells, respectively. 
A

\section{AGS control shRNA}

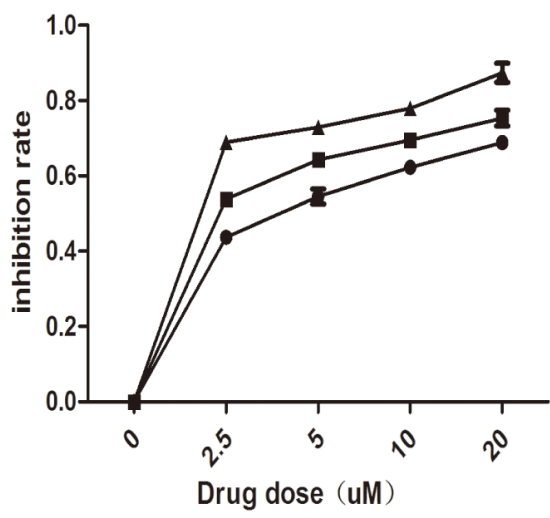

C

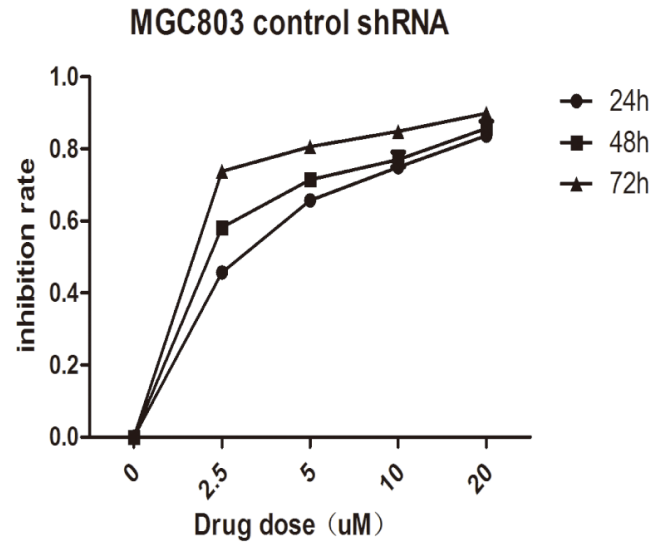

B
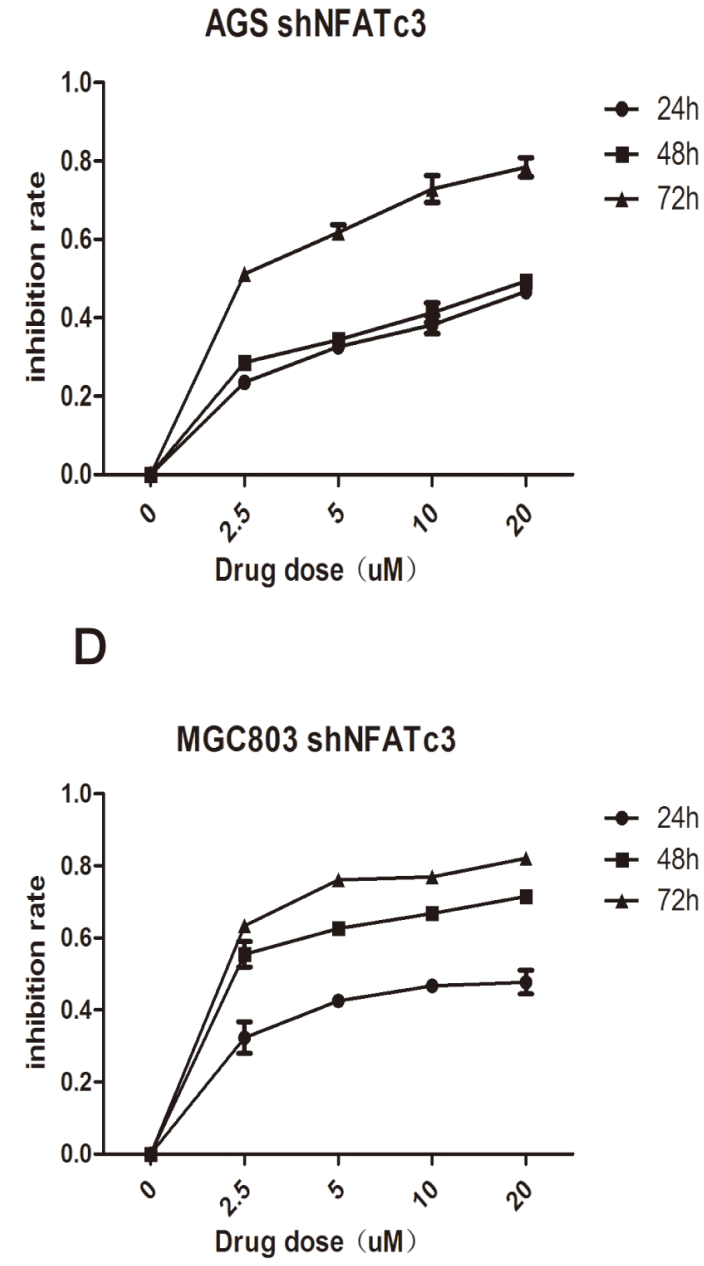

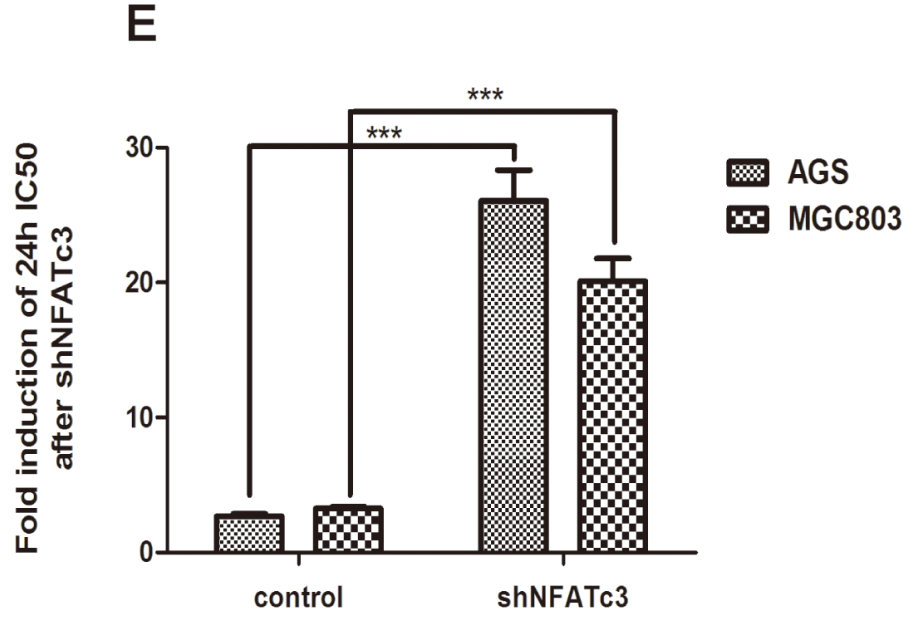

Figure 5: Curves of cell inhibition rates in GC cells treated with $\mathrm{As}_{4} \mathrm{~S}_{4}$ after the transfection of the Lentiviruses carrying NFATc3 shRNA. (A, C) Dose- and time-dependent curves of cell inhibition rates in cells treated with $\mathrm{As}_{4} \mathrm{~S}_{4}$ after the transfection of the Lentiviruses carrying control shRNA. (B, D) Dose- and time-dependent curves of cell inhibition rates in cells treated with $\mathrm{As}_{4} \mathrm{~S}_{4}$ after the transfection of the Lentiviruses carrying NFATc3 shRNA. (A, B) represent AGS cell, (C, D) represent MGC803 cell. (E) The fold change of $24 \mathrm{~h} \mathrm{IC}_{50}$ of GC cells to $\mathrm{As}_{4} \mathrm{~S}_{4}$ after the transfection of the Lentiviruses carrying NFATc3 shRNA. ***P $P 0.001$. 
MKN45, and SGC7901) and colon (HCT116, SW480, HT-29, LoVo, RKO, and Caco-2) cancer cell lines to explore their sensitivity to $\mathrm{As}_{4} \mathrm{~S}_{4} \cdot \mathrm{As}_{4} \mathrm{~S}_{4}$ inhibited the proliferation of all cell lines, and the range of $\mathrm{IC}_{50}$ values among GC cells is wider than that for colon cancer cells. We previously found that $\mathrm{As}_{4} \mathrm{~S}_{4}$ downregulated NFATc1, NFATc3, and NFATc4 levels in colon cancer cells, whileas long as p53 was intact-NFATc2 was up-regulated [17]. Similar results were found for GC MGC803 cells, except that NFATc2 was down-regulated because p53 is mutated in these cells [17]. We have further explored the role of NFATs in GC by detecting the baseline expression levels of NFAT family members including NFATc1-c4 in the aforementioned GC cell lines. Interestingly, the expression of NFATc 3 - but not other NFAT family members - varied among GC cells. However, this phenomenon was not obvious in the colon cancer cell lines examined. We then investigated whether NFATc3 expression is altered in GC patients by collecting 20 pairs of GC and corresponding adjacent normal tissues and measuring NFATc3 levels. NFATc3 was over-expressed in GC tissue compared with adjacent non-tumor tissue, consistent with our previous study of colon cancer patient samples [17], indicating that NFATc3 may act as a pro-tumorigenesis factor.

Consistently, altering the expression of NFATc3 revealed that it promotes the proliferation of GC cells and modulates the expression of c-Myc. In our previous research by chromatin IP (CHIP), we confirmed that NFATc3 indeed bond to the c-Myc promoter in colon cancer to yield increased levels of c-Myc [17]. c-Myc influences myriad cellular functions, including cell proliferation, survival, and microRNA expression [35].

\section{A}

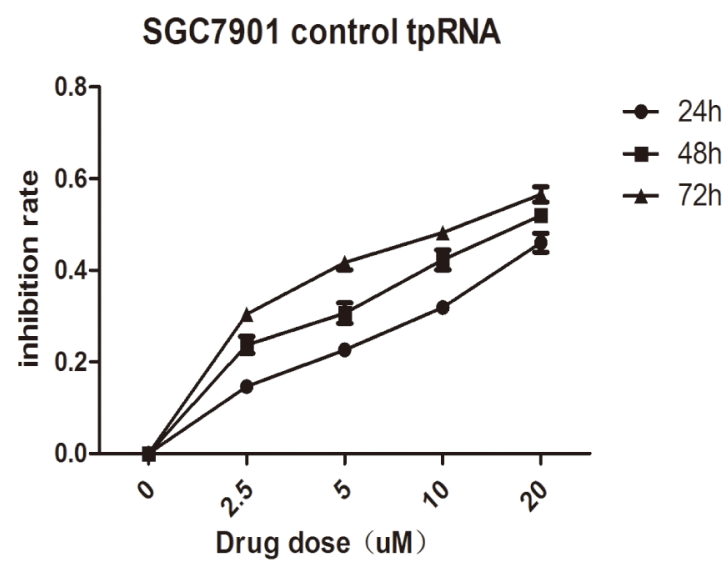

B
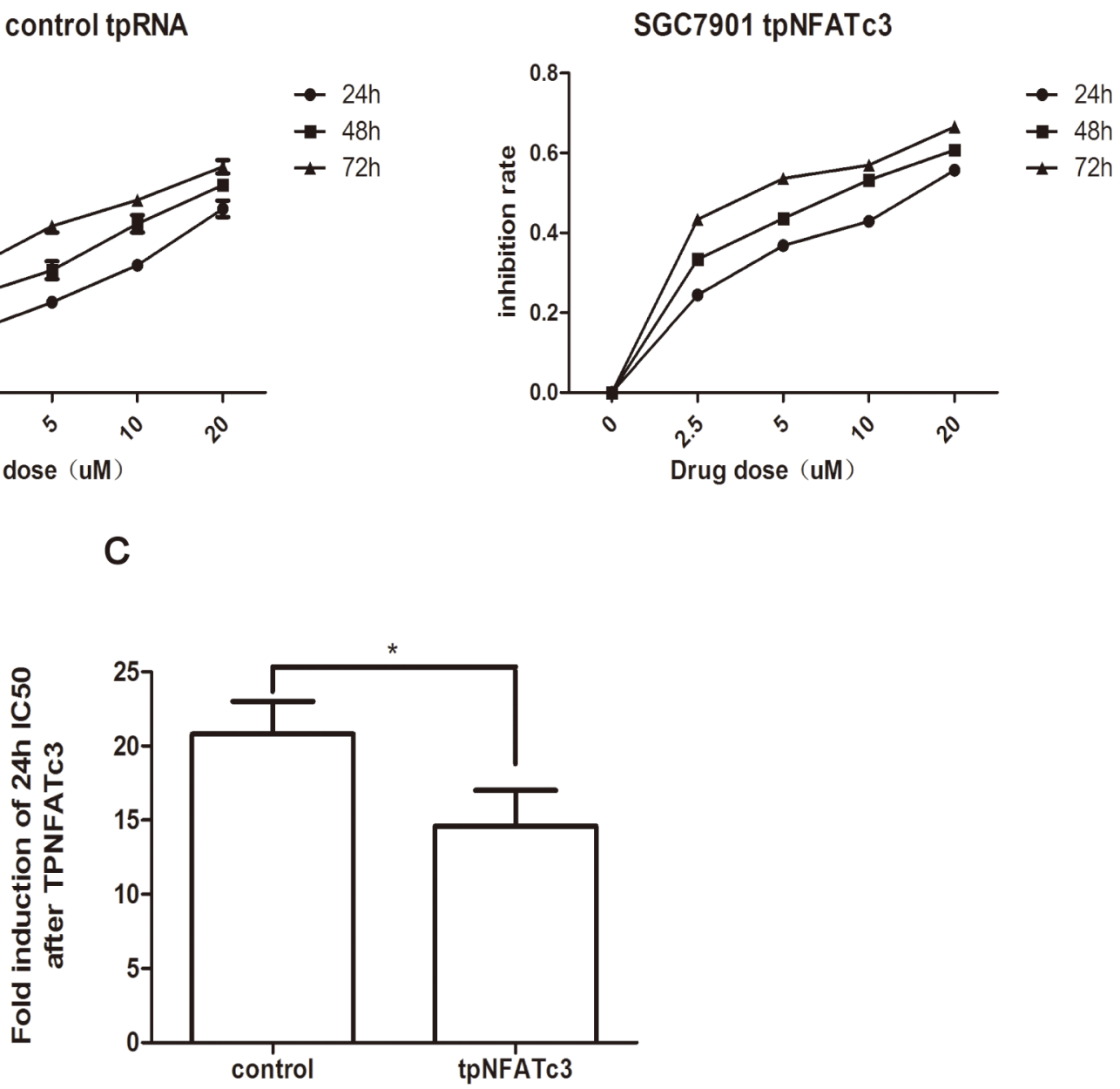

Figure 6: Curves of cell inhibition rates in SGC7901 cell treated with $\mathrm{As}_{4} \mathrm{~S}_{4}$ after the transfection of the plasmid carrying NFATc3 tpRNA. (A) Dose- and time-dependent curves of cell inhibition rates in cells treated with $\mathrm{As}_{4} \mathrm{~S}_{4}$ after the transfection of the plasmid carrying control tpRNA. (B) Dose- and time-dependent curves of cell inhibition rates in cells treated with $\mathrm{As}_{4} \mathrm{~S}_{4}$ after the transfection of the plasmid carrying NFATc3 tpRNA. (C) The fold change of $24 \mathrm{~h} \mathrm{IC}$ of $\mathrm{SGC7901}$ cells to $\mathrm{As}_{4} \mathrm{~S}_{4}$ after the transfection of the plasmid carrying NFATc 3 tpRNA. $* P<0.05$. 
Taken together with our previous findings that $\mathrm{As}_{4} \mathrm{~S}_{4}$ inhibits the proliferation of GC [20], we hypothesize that $\mathrm{As}_{4} \mathrm{~S}_{4}$ inhibits $\mathrm{GC}$ cell proliferation through downregulation of the NFATc3/c-Myc pathway.

We have revealed that NFATc3 promotes the proliferation of GC cells. Furthermore, NFATc3 expression is associated with the $\mathrm{IC}_{50}$ value for $\mathrm{As}_{4} \mathrm{~S}_{4}$, with higher levels of NFATc 3 conferring increased sensitivity to $\mathrm{As}_{4} \mathrm{~S}_{4}$, and vice versa. Consistently, knockdown of NFATc3 in cells relatively sensitive to $\mathrm{As}_{4} \mathrm{~S}_{4}$ (AGS and MGC803) decreased their sensitivity. Meanwhile, over-expression of NFATc3 in relatively resistant cells (SGC7901) increased their sensitivity to $\mathrm{As}_{4} \mathrm{~S}_{4}$. These findings support the notion that the sensitivity of GC cell lines to $\mathrm{As}_{4} \mathrm{~S}_{4}$ is associated with NFATc3 expression levels.

NFATc3 also regulates the expression of other NFAT family members. Knockdown of NFATc3 suppressed the expression of NFATc1 and NFATc4, while over-expression of NFATc3 had opposite effects. Our findings further highlight the versatility of the NFAT transcription factor family in modulating the behavior of cancer cells.

Taken together, our results show that the baseline expression of NFATc3 is related to the sensitivity to $\mathrm{As}_{4} \mathrm{~S}_{4}$. However, these interesting results are all based on in vitro studies, still need to be further validated in vivo. Now that NAFTc 3 could mediate the sensitivity of GC cells to $\mathrm{As}_{4} \mathrm{~S}_{4}$, whether it is associated with sensitivity of other drugs in other cancers should also be explored.

Collectively, the results obtained in the present study have demonstrated a novel role for NFATc3 in modulating drug response in GC. Importantly, these findings may implicate a new potential therapeutic target for the treatment of this deadly malignancy.

\section{MATERIALS AND METHODS}

\section{Ethical statement}

Investigation has been conducted in accordance with the ethical standards and according to the Declaration of Helsinki and according to national and international guidelines and has been approved by the authors' institutional review board.

\section{Cell culture and reagents}

The human GC cell lines AGS, MGC803, and SGC7901 were obtained from the Cell Bank, Chinese Academy of Sciences (Shanghai, People's Republic of China), MKN28 and MKN45 cells were obtained from Institute of Digestive of Shanghai Ruijin Hospital affiliated with Shanghai Jiao Tong University. No ethics statement was required from the institutional review board for the use of these cell lines. AGS cells were cultured in Dulbecco's modified Eagle medium (DMEM)/F12 1:1 medium
(Hyclone, Logan, UT, USA). MGC803 and SGC7901cells were cultured in RPMI 1640 medium (Gibco, Waltham, MA, USA). MKN28 and MKN45 cells were cultured in DMEM medium (Hyclone, Logan, UT, USA). All medium was supplemented with 10\% fetal bovine serum (Gibco, Waltham, MA, USA). All cells were cultured at $37^{\circ} \mathrm{C}$ in an atmosphere of $95 \%$ air and $5 \% \mathrm{CO}_{2}$. Highly purified $\mathrm{As}_{4} \mathrm{~S}_{4}$ was supplied by the Shanghai Institute of Hematology (Shanghai, People's Republic of China) and was prepared as previously described [20]. The stock solution of $\mathrm{As}_{4} \mathrm{~S}_{4}$ $(133.36 \mu \mathrm{M})$ was diluted in complete culture medium to obtain working solutions. 3-(4, 5-dimethylthiazol-2-yl)-2, 5-diphenyltetrazolium bromide (MTT) was purchased from Sigma-Aldrich (St Louis, MO, USA). Antibodies for NFATAc1, NFATAc3, and NFATAc4 were purchased from Sigma-Aldrich (St Louis, MO, USA), Santa Cruz Biotechnology (Santa Cruz, CA, USA), and Abcam (Cambridge, MA, USA), respectively. Antibody for c-Myc was from Cell Signaling Technology (Beverly, MA, USA), while anti- $\beta$-actin antibody was obtained from Proteintech Group (Wuhan, Hubei, People's Republic of China).

\section{Cytotoxicity assay}

The cytotoxicity assay was performed as previously described [36]. Briefly, MKN28, MKN45, or SGC7901 cells $\left(5 \times 10^{3}\right.$ cells/well, in $90 \mu \mathrm{L}$ medium $)$ were seeded into 96-well plates and allowed to attach. The following day, $\mathrm{As}_{4} \mathrm{~S}_{4}$ at different concentrations (in $10 \mu \mathrm{L}$ volumes) was administered to cells. Then, $10 \mu \mathrm{L}$ MTT $(5 \mathrm{mg} /$ $\mathrm{mL}$ ) was added to designated wells after 24, 48, or $72 \mathrm{~h}$ and incubated at $37^{\circ} \mathrm{C}$ for $4 \mathrm{~h}$. Thereafter, $150 \mu \mathrm{L}$ sodium dodecyl sulfate (SDS) was added to each well and incubated at $37^{\circ} \mathrm{C}$ overnight. The optical density at $562 \mathrm{~nm}$ was measured using a microplate reader (BioTEK, Vermont, USA). Cells incubated without any treatment were used as control. Culture medium without cells was used as blank control. The $\mathrm{IC}_{50}$ (concentration causing 50\% inhibition of cell growth compared with the control) value of $\mathrm{As}_{4} \mathrm{~S}_{4}$ for each of the tumor cell lines was calculated after $24 \mathrm{~h}$. Data were analyzed based on three independent experiments. The $\mathrm{IC}_{50}$ values for AGS and MGC803 cells were calculated using the same method described in our previous study [20].

\section{Western blotting}

Total proteins were extracted using enhanced radioimmunoprecipitation assay lysis buffer (Beyotime, Shanghai, China) containing 1\% phenylmethanesulfonyl fluoride (Beyotime) on ice. Protein concentrations were determined using a microplate reader (Bio-TEK) with the enhanced bicinchoninic acid protein assay kit (Beyotime). Equal amounts of protein in each lane were separated by different SDS-polyacrylamide gel electrophoresis according to the molecular weight of measured proteins 
and transferred onto a polyvinylidene difluoride membrane (Millipore, Billerica, MA, USA). After blocking the membrane in 5\% non-fat milk, the membrane was then incubated with diluted primary antibodies at $4^{\circ} \mathrm{C}$ overnight. Membranes were then washed three times with tris-buffered saline with Tween 20 (the percentage of Tween 20 was $0.05 \%$ ) and incubated with labeled secondary antibody at room temperature for $1 \mathrm{~h}$, and then washed thrice again. Finally, proteins were detected using the ECL Plus kit (Millipore), and images were acquired using the GelDoc XR System (Bio-rad, USA).

\section{Infection with shRNA-encoding lentivirus}

Lentiviruses (pHBLV-U6-Zsgreen) encoding NFATc3 shRNA (shNFATc3) were provided by HanBio (Shanghai, China). AGS and MGC803 cells were grown to $30-40 \%$ confluence in 6-well culture plates and then infected with lentivirus encoding shRNA according to the manufacturer's instructions. Briefly, $5 \mu \mathrm{L}$ Polybrene was added to each well and incubated at $37^{\circ} \mathrm{C}$ for 30 min, followed by addition of required amounts lentivirus according to the multiplicity of infection of specific cells. Infection efficiency was observed by fluorescence microscopy on the basis of GFP expression, and further confirmed by measuring protein levels of NFATc3. After a $12 \mathrm{~h}$ incubation at $37^{\circ} \mathrm{C}$, cells were washed and incubated with fresh medium for an additional $60 \mathrm{~h}$ before analysis; culture medium was replaced daily. The shRNA sequences were the same as those previously used [17].

\section{pMAX-clover-NFATc3 plasmid construction and transfection}

The pMAX-clover-NFATc3 vector for over-expression of NFATc3 was constructed by PCR amplification of the primary NFATc3 sequence (3228 bp) from human cDNA using the primers $5^{\prime}$-AGAATTCATGACTACTGCAAA CTGTGG-3' (forward) and 5'-GCGTCGACTTAGAG CCCATCAGATCTTC-3' (reverse), and cloning of this sequence downstream of the clover sequence in the pMAXclover vector using the EcoRI/SalI sites. SGC7901 cells were grown in 6-well culture plates and then transfected with pMAX-clover-NFATc3 using Lipofectamine 2000 (Invitrogen, USA) according to the manufacturer's instructions. Briefly, Lipofectamine 2000 and pMAX-cloverNFATc3 were diluted in opti-MEM medium, incubated for $5 \mathrm{~min}$, mixed together, and then incubated for $30 \mathrm{~min}$ at room temperature. Finally, complexes were added to wells containing cells. The transfection efficiency was observed as described above.

\section{MTT and colony formation assays}

AGS and MGC803 cells infected with lentiviruses carrying shNFATc3 and SGC7901 cells transfected with plasmid encoding NFATc3 were subjected to
MTT assay. MTT assays were conducted in a similar manner to the cytotoxicity assay described above. For the colony formation assay, cells were trypsinized to generate a single-cell suspension, and 2000 cells/well were seeded into 6 -well plates followed by incubation under normal conditions for 2 weeks. Colonies were fixed with $4 \%$ paraformaldehyde for $15 \mathrm{~min}$ at room temperature and then stained with Giemsa staining fluid for $20 \mathrm{~min}$. Colonies were then counted under a light microscope.

\section{Patients and tissue samples}

The GC samples and their corresponding adjacent normal tissues were obtained from 20 patients diagnosed with GC and treated with surgery at the Xinhua Hospital Affiliated with Shanghai Jiao Tong University of Medicine (Shanghai, China). All samples and clinical information were obtained with informed consent from the patient or their family. Tissues were immediately snap-frozen in liquid nitrogen after surgery and stored at $-80^{\circ} \mathrm{C}$ until RNA extraction. This study was approved by the ethics committee of Xinhua Hospital Affiliated to Shanghai Jiao Tong University.

\section{Statistical analysis}

SPSS software version 20.0 (IBM Corporation, Armonk, NY, USA) was used for all statistical analyses. Experiments were repeated independently three times and all data are presented as the means \pm standard deviation (SD). Data analysis was performed using oneway analysis of variance, followed by either the least significant difference procedure (if variance was equal) or the Games-Howell procedure (if variance was unequal). A two-sided $P$-value of $<0.05$ was considered statistically significant.

\section{Author contributions}

Xiuli Zhang designed and performed most of the experiments. Ting Kang constructed the plasmid. Lian Zhang performed some western blotting experiment. Yingying Tong and Wenping Ding provided some advises. Siyu Chen conceived the concept, designed and supervised all the experiments.

\section{ACKNOWLEDGMENTS}

We thank Shanghai Institute of Hematology for providing us condition to construct pMAX-clover-NFATc3 plasmid.

\section{CONFLICTS OF INTEREST}

The authors have no conflicts of interest to disclose. 


\section{FUNDING}

This work was partly funded by the National Science Foundation of China grants (81274142), the Natural Science Foundation of Science and Technology Commission of Shanghai Municipality (11ZR1423400), and the Key Project of Shanghai Municipal Education Commission (07zz43).

\section{REFERENCES}

1. Jemal A, Bray F, Center MM, Ferlay J, Ward E, Forman D. Global cancer statistics. CA Cancer J Clin. 2011; 61:69-90.

2. Shi Y, Zhou Y. The role of surgery in the treatment of gastric cancer. J Surg Oncol. 2010; 101:687-92.

3. Wagner AD, Grothe W, Haerting J, Kleber G, Grothey A, Fleig WE. Chemotherapy in advanced gastric cancer: a systematic review and meta-analysis based on aggregate data. J Clin Oncol. 2006; 24:2903-2909.

4. Kim SJ, Wang YG, Lee HW, Kang HG, La SH, Choi IJ, Irimura T, Ro JY, Bresalier RS, Chun KH. Up-regulation of neogenin-1 increases cell proliferation and motility in gastric cancer. Oncotarget. 2014; 5:3386-3398. doi: 10.18632/oncotarget.1960.

5. Long ZW, Yu HM, Wang YN, Liu D, Chen YZ, Zhao YX, Bai L. Association of IL-17 polymorphisms with gastric cancer risk in Asian populations. World Journal of Gastroenterology. 2015; 21:5707-18.

6. Shaw JP, Utz PJ, Durand DB, Toole JJ, Emmel EA, Crabtree GR. Identification of a putative regulator of early T cell activation genes. Science. 1988; 241:202-205.

7. Durand DB, Shaw JP, Bush MR, Replogle RE, Belagaje R, Crabtree GR. Characterization of antigen receptor response elements within the interleukin-2 enhancer. Mol Cell Biol. 1988; 8:1715-1724.

8. Crabtree GR, Olson EN. NFAT signaling: choreographing the social lives ofcells. Cell. 2002; 109:S67-S79.

9. Hogan PG, Chen L, Nardone J, Rao A. Transcriptional regulation by calcium, calcineurin, and NFAT. Genes Dev. 2003; 17:2205-2232.

10. Negishi-Koga T, Takayanagi H. Ca2+-NFATc1 signaling is an essential axis of osteoclast differentiation. Immunol Rev. 2009; 231:241-56.

11. Horsley V, Aliprantis AO, Polak L, Glimcher LH, Fuchs E. NFATc1 balancesquiescence and proliferation of skin stem cells. Cell. 2008; 132:299-310.

12. Mancini M, Toker A. NFAT proteins: emerging roles in cancer progression. Nat Rev Cancer. 2009; 9:810-20.

13. Muller MR, Rao A. NFAT, immunity and cancer: a transcription factor comes of age. Nat RevImmunol. 2010; 10:645-56.

14. Medyouf H, Ghysdael J. The calcineurin/NFAT signaling pathway: a noveltherapeutic target in leukemia and solid tumors. Cell Cycle. 2008; 7:297-303
15. Wang S, Kang X, Cao S, Cheng H, Wang D, Geng J. Calcineurin/NFATc1 Pathway Contributes to Cell Proliferation in Hepatocellular Carcinoma. Dig Dis Sci. 2012; 57:3184-8.

16. Foldynová-Trantírková S, Sekyrová $\mathrm{P}$, Tmejová K, Brumovská E, Bernatík O, Blankenfeldt W, Krejcí P, Kozubík A, Dolezal T, Trantírek L, Bryja V. Breast cancerspecific mutations in CK1 epsilon inhibit Wnt/beta-catenin and activate the Wnt/Rac1/JNK and NFAT pathways to decrease cell adhesion and promote cell migration. Breast Cancer Res. 2010 ;12:R30.

17. Ding W, Tong Y, Zhang X, Pan M, Chen S. Study of Arsenic Sulfide in Solid Tumor Cells Reveals Regulation of Nuclear Factors of Activated T-cells by PML and p53. Sci Rep. 2016; 6:19793.

18. Robbs BK, Cruz AL, Werneck MB, Mognol GP, Viola JP. Dual roles for NFAT transcription factor genes as oncogenesand tumor suppressors. Mol Cell Biol. 2008; 28:7168-81.

19. Glud SZ, Sorensen AB, Andrulis M, Wang B, Kondo E, Jedden R, Krenacs L, Stelkovics E, Wabl M, Serfling E, Palmetshofer A, Pedersen FS. A tumor-suppressor function for NFATc3 in T-cell lymphomagenesis by murine leukemia virus. Blood.2005; 106:3546-52.

20. Zhang L, Tian W, Kim S, Ding W, TongY, Chen S. Arsenic sulfide, the main component of realgar, a traditional Chinese medicine, induces apoptosis of gastric cancer cells in vitro and in vivo. Drug Des Devel Ther. 2014; 9:79-92.

21. Nardone G, Compare D. Epigenetic alterations due to diet and Helicobacter pylori infection in gastric carcinogenesis. Expert Rev Gastroenterol Hepatol. 2008; 2:243-8.

22. Baumgart S, Glesel E, Singh G, Chen NM, Reutlinger K, Zhang J, Billadeau DD, Fernandez-Zapico ME, Gress TM, Singh SK, Ellenrieder V. Restricted heterochromatin formation links NFATc2 repressor activity with growth promotion in pancreatic cancer. Gastroenterology. 2012; 142:388-98.

23. Koenig A, Linhart T, Schlengemann K, Reutlinger K, Wegele J, Adler G, Singh G, Hofmann L, Kunsch S, Buch T, Schafer E, Gress TM, Fernandez-Zapico ME, et al. NFAT-induced histone acetylation relay switch promotes c-Myc dependent growth in pancreatic cancer cells. Gastroenterology. 2010 ; 138:1189-99.

24. Buchholz M, Schatz A, Wagner M, Michl P, Linhart T, Adler G, Gress TM, Ellenrieder V. Overexpression of c-myc in pancreatic cancer caused by ectopic activation of NFATc 1 and the Ca2t/calcineurin signaling pathway. EMBO J. 2006; 25:3714-24.

25. Medyouf H, Alcalde H, Berthier C, Guillemin MC, dos Santos NR, Janin A, Decaudin D, de The H, Ghysdael J. Targeting calcineurin activation as a therapeuticstrategy for T-cell acute lymphoblastic leukemia. Nat Med. 2007; $13: 736-41$. 
26. Pham LV, Tamayo AT, YoshimuraLC, Lin-Lee YC, Ford RJ. Constitutive NF-kappaB and NFAT activation in aggressive B-cell lymphomas synergisticallyactivates the CD154 gene and maintains lymphoma cell survival. Blood. 2005; 106:3940-3947.

27. Yoeli-Lerner M, Chin YR, Hansen CK, Toker A. Akt/ protein kinase $\mathrm{b}$ and glycogen synthase kinase-3beta signaling pathway regulates cell migration through the NFAT1 transcription factor. Mol Cancer Res. 2009; 7:425-32.

28. Yoeli-Lerner M, Yiu GK, Rabinovitz I, Erhardt P, Jauliac S, Toker A. Akt blocks breast cancer cell motility and invasion through the transcription factor NFAT. Mol Cell. 2005; 20:539-550.

29. Flockhart RJ, Armstrong JL, Reynolds NJ, Lovat PE. NFAT signalling is a novel target of oncogenic BRAF in metastatic melanoma. Br J Cancer. 2009; 101:1448-55.

30. Murray OT, Wong CC, Vrankova K, Rigas B. Phosphosulindac inhibits pancreatic cancer growth: NFATc1 as a drug resistance candidate. Int J Oncol. 2014; 44:521-9.

31. Gregory MA, Phang TL, Neviani P, Alvarez-Calderon F, Eide CA, O'Hare T, Z Zaberezhnyy V, Williams RT, Druker BJ, Perotti D, Degregori J. Wnt/Ca2+/NFAT signaling maintains survival of $\mathrm{Ph}+$ leukemia cells upon inhibition of Bcr-Abl. Cancer Cell. 2010; 18:74-87.

32. Perotti V, Baldassari P, Bersani I, Molla A, Vegetti C, Tassi E, Dal Col J, Dolcetti R, AnichiniA, Mortarini R. NFATc2is a potential therapeutic target in human melanoma. Invest Dermatol. 2012; 132:2652-2660.

33. Cippa PE, Kraus AK, Lindenmeyer MT, Chen J, Guimezanes A, Bardwell PD, Wekerle T, Wuthrich RP, Fehr T. Resistance to ABT-737 in activated T lymphocytes:molecular mechanisms and reversibility by inhibition of the calcineurin-NFAT pathway. Cell Death Dis. 2012 19; 3:e299.

34. Spreafico A, Tentler JJ, Pitts TM, Tan AC, Gregory MA, Arcaroli JJ, Klauck PJ, McManus MC, Hansen RJ, Kim J, Micel LN, Selby HM, Newton TP, et al. Rational combination of a MEK inhibitor, selumetinib, and the Wnt/ calcium pathway modulator, cyclosporin $\mathrm{A}$, in preclinical models of colorectal cancer. Clin. Cancer Res. 2013; 19:4149-4162.

35. Dang CV, O’Donnell KA, Zeller KI, Nguyen T, Osthus RC, Li F. The c-Myc target gene network. Semin Cancer Biol. 2006; 16:253-264.

36. Ding W, Zhang L, Kim SK, Tian W, Tong Y, Liu J, Ma Y, Chen S. Arsenic sulfide as a potential anti-cancer drug. Mol Med Rep. 2015; 11:968-74. 